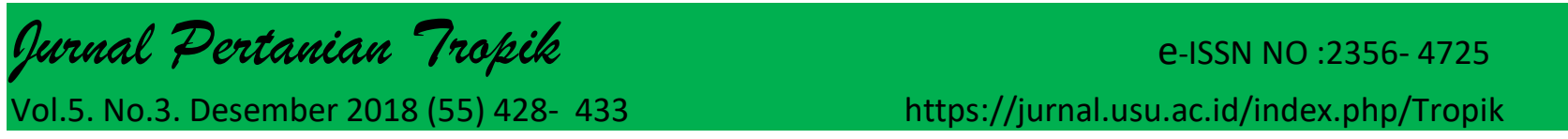

\title{
Efficiency Use of Nitrogen In Several Palm Oil Varieties With Treatment of Nitrogen Fertilizer Levels In Main Nursery
}

\section{Efisiensi Penggunaan Nitrogen Beberapa Varietas Kelapa Sawit Dengan Perlakuan Tingkat Pemberian Pupuk Nitrogen Di Pembibitan Utama}

\author{
Muhammad Afrillah", Chairani Hanum, Abdul Rauf \\ Departemen Program Studi Magister Agroteknologi, Fakultas Pertanian, USU, Medan 20155 \\ *Corresponding author: m.afrillah@ymail.com
}

\begin{abstract}
Efficiency use of nitrogen in several palm oil varieties with treatment in nitrogen fertilizer level in main nursery. This study aims to determine the growth characteristics of several varieties of palm oil efficient use of nitrogen with the provision of various nitrogen levels in the main nursery. The research was conducted in the nursery area of Yos Sudarso Binjai road and the Soil Laboratory of the Palm Oil Research Center, Medan from May to November 2017, using a factorial randomized block design with two factors. The first factor is varieties consisting of 7 types namely Avros, Simalungun, PPKS 540, Yangambi, PPKS 718, PPKS 239, Langkat. The second factor is the N fertilization dose consisting of 5 levels ie 0, 25, 50, 75 and 100\% from fertilizer recommendation. The results showed that the addition of $N$ level increased the dry weight of the canopy, and the uptake of plant $N$ nutrients. The efficient use of optimal Nitrogen in Yangambi varieties was obtained on N 25\% fertilization, while Avros and PPKS 239 were at 50\% recommendation level. $75 \%$ recommendation produce optimal value efficient use of $N$ on Simalungun variety, PPKS 718, and Langkat. PPKS 540 varieties efficient use of $N$ optimal at 100\% recommendation level.
\end{abstract}

Key Words: Main Nursery, $N$ Fertilizers, Oil Palm, Varieties.

\begin{abstract}
ABSTRAK
Efisiensi penggunaan nitrogen beberapa varietas kelapa sawit dengan perlakuan tingkat pemberian pupuk nitrogen di pembibitan utama. Penelitian ini bertujuan untuk mengetahui varietas kelapa sawit yang efisien penggunaan nitrogen dengan pemberian berbagai taraf $\mathrm{N}$ di pembibitan utama. Penelitian dilaksanakan di areal pembibitan jalan Yos Sudarso Binjai dan Laboratorium Tanah Pusat Penelitian Kelapa Sawit, Medan dari Mei sampai November 2017, menggunakan rancangan acak kelompok faktorial dengan dua faktor. Faktor pertama adalah varietas yang terdiri dari 7 jenis yakni Avros, Simalungun, PPKS 540, Yangambi, PPKS 718, PPKS 239, Langkat. Faktor kedua adalah dosis pemupukan $\mathrm{N}$ yang terdiri dari 5 taraf yaitu $0,25,50,75$ dan $100 \%$ dari rekomendasi pemupukan. Hasil penelitian menunjukan bahwa penambahan taraf pemberian $\mathrm{N}$ meningkatkan bobot kering tajuk, dan serapan hara $\mathrm{N}$ tanaman. Nilai efisien penggunaan $\mathrm{N}$ optimal pada varietas Yangambi diperoleh pada pemupukan N 25\%, sedangkan Avros dan PPKS 239 pada taraf 50\% rekomendasi. Taraf $75 \%$ rekomendasi menghasilkan nilai optimal efisien penggunaan $\mathrm{N}$ pada varietas Simalungun, PPKS 718, dan Langkat. Varietas PPKS 540 efisien penggunaan N optimal pada taraf $100 \%$ rekomendasi.
\end{abstract}

Kata-kata kunci: Kelapa Sawit, Pembibitan Utama, Pupuk N, Varietas 


\section{PENDAHULUAN}

Kelapa sawit sangat berperan penting dalam peningkatan devisa negara. Indonesia merupakan produsen minyak sawit utama dunia. Selain itu perkebunan kelapa sawit berperan dalam penyerapan tenaga kerja serta peningkatan perekonomian di Indonesia. Luas pertanaman sawit di Indonesia juga semakin meningkat dari tahun ke tahun yaitu mencapai 11,3 juta ha pada tahun 2015 yang terdiri dari perkebunan besar dan perkebunan rakyat (Direktorat Jendral Perkebunan, 2015).

Peningkatkan produktivitas tanaman kelapa sawit, ada beberapa faktor yang dapat diperhatikan yaitu penggunaan bibit yang berkualitas, pemeliharaan yang baik serta pemupukan yang tepat (Ramadhaini, et al, 2014). Untuk menghasilkan fungsi pemupukan hal yang harus diperhatikan adalah jenis pupuk yang diberikan, cara aplikasi dan dosis pemupukan, serta varietas yang respons dalam pemberian pupuk.

Pembibitan merupakan rangkaian kegiatan mempersiapkan bahan tanam sebelum ke lapangan. Pemupukan pada pembibitan kelapa sawit dilakukan dengan memberikan pupuk $\mathrm{N}$. Nitrogen diambil tanaman untuk proses asimilasi karena hara $\mathrm{N}$ yang mudah tercuci sementara di sisi lain hara $\mathrm{N}$ merupakan kebutuhan vital bagi tanaman. Selama lebih 40 tahun peningkatan penggunaan pupuk $\mathrm{N}$ mencapai $\mathrm{N}$ meningkatkan 7,4 kali lebih besar sementara peningkatan produksi hanya 2,4. Hal ini membuktikan bahwa efisiensi penggunaan nitrogen (EPN) merupakan satu alternatif untuk memprediksi ketersediaan $\mathrm{N}$ di dalam tanah. Hasil ini mengimplikasikan bahwa EPN yang tinggi terjadi jika $\mathrm{N}$ yang diberikan dari proses pemupukan lebih rendah. EPN merupakan gambaran dari efisiensi absorpsi dan efisiensi penggunaan hara N. Masing masing varietas memiliki keragaman dalam absorpsi efisiensi $\mathrm{N}$ maupun efisiensi penggunaan $\mathrm{N}$

(Hirel et al. 2007).

Dengan banyaknya varietas yang baru saat ini penting untuk mengkaji bagaimana pertumbuhan dan efisiensi penggunaan nitrogen sehingga dapat diketahui dosis pemakaian pupuk sesuai dengan kebutuhan tanaman sebagai total produksi tanaman per unit $\mathrm{N}$ yang diserap. Efisiensi penggunaan $\mathrm{N}$ dapat memungkinkan pekebun untuk memaksimalkan hasil di bawah tingkat pemupukan $\mathrm{N}$ yang moderat, bukan tingkat penggunaan $\mathrm{N}$ yang tinggi (Anbessa dan Juskiw, 2012; Bingham et al. 2012).

Identifikasi pertumbuhan bibit kelapa sawit di pembibitan akan menggambarkan pola mutu bibit yang baik sebelum dipindah tanamkan ke lapangan dan menduga kebutuhan pupuk $\mathrm{N}$ yang efisien dan efektif.

Tujuan penelitian dilakukan untuk mengetahui varietas bibit kelapa sawit yang efisien penggunaan nitrogen dengan perlakuan berbagai taraf pemupukan $\mathrm{N}$ di pembibitan utama.

\section{BAHAN DAN METODE}

Penelitian ini dilaksanakan di jalan Yos Sudarso binjai dan Laboratorium Tanah Pusat Penelitian Kelapa Sawit, Medan. Penelitian dilaksanakan mulai bulan Mei sampai dengan bulan Oktober 2017 Penelitian menggunakan Rancangan Acak Kelompok (RAK) Faktorial dengan dua faktor, pertama ialah Varietas terdiri dari 7 jenis, yaitu: V1 = DxP AVROS, V2 = DxP Simalungun, V3 = DxP PPKS 540, V4 = DxP Yangambi, V5 = DxP PPKS 718, V6 = DxP PPKS 239, V7 = DxP Langkat dan kedua yaitu Dosis pemupukan $\mathrm{N}$ terdiri dari 5 taraf, yaitu : $\mathrm{D} 0=$ Tanpa pemberian pupuk N, D1 $=25 \%, \mathrm{D} 2=$ $50 \%, \mathrm{D} 3=75 \%, \mathrm{D} 4=100 \%$ rekomendasi pupuk. Data dianalisis dengan analisis ragam, jika terdapat pengaruh nyata maka dilanjutkan dengan Uji Jarak Berganda Duncan.

Pemupukan urea dilakukan sesuai dengan taraf perlakuan. Pemupukan dilakukan dengan cara tabur sampai bibit berumur 9 bulan dengan taraf pemupukan berdasarkan perlakuan pupuk $\mathrm{N}$ (Urea) yang dapat dilihat pada Tabel 1.

Peubah amatan yang diamati adalah bobot kering tajuk, serapan hara $\mathrm{N}$ dan efisiensi penggunaan $\mathrm{N}$. 
Tabel 1. Tingkatan dosis pemupukan

\begin{tabular}{llllll}
\hline \multirow{2}{*}{$\begin{array}{l}\text { Umur } \\
\text { Bibit } \\
\text { bulan) }\end{array}$} & \multicolumn{5}{c}{ Dosis Pupuk (g/bibit) } \\
\cline { 2 - 5 } & $100 \%$ & $75 \%$ & $50 \%$ & $25 \%$ & $0 \%$ \\
\hline 4 & 1,5 & 1,125 & 0,75 & 0,375 & 0 \\
5 & 1,5 & 1,125 & 0,75 & 0,375 & 0 \\
6 & 2 & 1,5 & 1 & 0,5 & 0 \\
7 & 3 & 2,25 & 1,5 & 0,75 & 0 \\
8 & 4 & 3 & 2 & 1 & 0 \\
9 & 5 & 3,75 & 2,5 & 1,25 & 0 \\
\hline
\end{tabular}

\section{HASIL DAN PEMBAHASAN}

\section{Bobot Kering Tajuk}

Hasil analisis statistik menunjukkan bahwa dosis pemupukan $\mathrm{N}$ berpengaruh nyata terhadap parameter bobot kering tajuk, sedangkan ketujuh varietas dan interaksi kedua perlakuan tidak menunjukan perbedaan yang nyata

Varietas Simalungun memliki rataan bobot kering tajuk tertinggi sedangkan PPKS 239 menghasilkan rataan terendah, walaupun secara statistik tidak berbeda nyata. Perlakuan dosis $100 \%$ rekomendasi pemupukan menghasilkan rataan bobot kering tajuk tertinggi sedangkan pemberian dosis $50 \%$ rekomendasi pemupukan menghasilkan rataan terendah (Tabel 2).
Bobot kering tanaman (akar dan tajuk) menunjukkkan tingkat efesiensi metabolisme dari tanaman tersebut. Akumulasi bahan kering digunakan sebagai indikator ukuran pertumbuhan. Akumulasi bahan kering mencerminkan kemampuan tanaman dalam mengikat energy dari cahaya matahari melalui proses fotosintesis, serta interaksi dengan faktor lingkungan lainnya (Fried \& Hademenos, 2000). Perlakuan dosis pemupukan $\mathrm{N}$ berpengaruh nyata terhadap parameter bobot kering tajuk. Dari hasil pengamatan diperoleh perlakuan dosis $100 \%$ rekomendasi pemupukan menghasilkan rataan bobot kering tajuk tertinggi yaitu sebesar $91,1 \mathrm{~g}$, sedangkan perlakuan dosis $50 \%$ rekomendasi pemupukan menghasilkan rataan terendah yakni sebesar $49 \mathrm{~g}$.

Tabel 2. Bobot kering tajuk bibit kelapa sawit pada perlakuan varietas dan dosis pemupukan $\mathrm{N}$

\begin{tabular}{|c|c|c|c|c|c|c|}
\hline \multirow{2}{*}{ Varietas } & \multicolumn{5}{|c|}{ Dosis Pemupukan N } & \multirow{2}{*}{ Rataan } \\
\hline & 0 & $25 \%$ & $50 \%$ & $75 \%$ & $100 \%$ & \\
\hline Avros & 45 & 34 & ......g....... & 82 & .................. & 64,3 \\
\hline Simalungun & 98 & 104 & 49 & 96 & 70 & 83,7 \\
\hline PPKS 540 & 69 & 72 & 50 & 52 & 100 & 69 \\
\hline Yangambi & 43 & 84 & 32 & 72 & 63 & 59,1 \\
\hline PPKS 718 & 36 & 58 & 44 & 82 & 143 & 72,9 \\
\hline PPKS 239 & 44 & 56 & 61 & 63 & 66 & 58,3 \\
\hline Langkat & 42 & 48 & 42 & 85 & 95 & 62,7 \\
\hline Rataan & $54,1 \mathrm{~d}$ & $65,6 \mathrm{c}$ & $49 \mathrm{~d}$ & $76,1 \mathrm{~b}$ & $91,1 \mathrm{a}$ & 67,1 \\
\hline
\end{tabular}

Keterangan: Angka yang diikuti notasi yang sama pada kolom yang sama menunjukkan berbeda tidak nyata menurut Uji Jarak Berganda Duncan pada taraf 5\%. 


\section{Serapan Hara N}

Hasil analisis statistik menunjukkan bahwa dosis pemupukan $\mathrm{N}$ berpengaruh nyata terhadap parameter serapan hara $\mathrm{N}$ tanaman, sedangkan ketujuh varietas dan interaksi antara kedua perlakuan tidak menunjukkan perbedaan yang nyata. Rataan serapan hara $\mathrm{N}$ tanaman dapat dilihat pada Tabel 3.

Hasil pada tabel 3 menunjukkan bahwa Varietas Simalungun menghasilkan rataan serapan hara $\mathrm{N}$ tertinggi $(192,12 \mathrm{mg})$ sedangkan Langkat menghasilkan rataan terendah (143,58 mg), walaupun secara $100 \%$ rekomendasi pemupukan menghasilkan rataan serapan hara $\mathrm{N}$ tertinggi yaitu sebesar 222,81 mg sedangkan terendah didapat pada perlakuan tanpa pemupukan yakni sebesar $120,17 \mathrm{mg}$.

Penyerapan unsur hara erat kaitannya dengan proses fotosintesis, proses tersebut akan menghasilkan fotosintat yang akan disalurkan dari daun keseluruh bagian tanaman. Semakin tersedia unsur hara dan semakin bagus penyerapan hara maka proses metabolisme akan semakin baik, sehingga kualitas dan kuantitas tanaman akan semakin bagus.

Parameter serapan hara $\mathrm{N}$ tanaman perlakuan dosis pemupukan memberikan hasil yang berpengaruh nyata. Perlakuan dosis
$100 \%$ rekomendasi pemupukan menghasilkan rataan serapan hara $\mathrm{N}$ tertinggi yaitu sebesar 222,81 mg sedangkan terendah didapat pada perlakuan tanpa pemupukan yakni sebesar 120,17 mg. Serapan N pada dosis $100 \%$ rekomendasi pemupukan lebih tinggi dibanding pemberian dosis rekomendasi lainnya. Pemberian dosis pemupukan yang cukup berperan dalam menambah kandungan unsur hara nitrogen tersedia yang dibutuhkan oleh bibit kelapa sawit untuk mendukung pertumbuhan vegetatif bibit secara optimum, dengan pertumbuhan vegetatif yang baik maka bibit dapat melakukan proses metabolisme dalam tubuh secara maksimal khususnya fotosintesis dimana hasil dari proses fotosintesis yang berbentuk asimilat bisa dikonversi menjadi energi yang berguna bagi tanaman untuk melangsungkan proses statistik tidak berbeda nyata. Perlakuan dosis pertumbuhan dan perkembangan. Nyakpa et al. (1988) menyatakan bahwa nitrogen adalah penyusun utama berat kering tanaman muda dibanding tanaman yang lebih tua, dengan unsur hara nitrogen yang tercukupi pada bibit maka berat kering tanaman akan lebih tinggi jika dibandingkan dengan bibit yang kekurangan nitrogen.

Tabel 3. Serapan hara $\mathrm{N}$ tanaman pada perlakuan varietas dan dosis pemupukan

\begin{tabular}{lllllll}
\hline \multirow{2}{*}{ Varietas } & \multicolumn{5}{c}{ Dosis Pemupukan } & \multirow{2}{*}{ Rataan } \\
\cline { 2 - 6 } & 0 & $25 \%$ & $50 \%$ & $75 \%$ & $100 \%$ & \\
\hline \multirow{2}{*}{ Avros } & $\ldots \ldots \ldots \ldots \ldots \ldots \ldots \ldots$ & $\ldots \ldots \ldots \ldots$ \\
Simalungun & 92,32 & 78,00 & 158,63 & 219,09 & 276,10 & 164,83 \\
PPKS 540 & 205,36 & 245,60 & 118,48 & 242,07 & 149,12 & 192,12 \\
Yangambi & 165,52 & 188,53 & 109,13 & 126,19 & 238,78 & 165,63 \\
PPKS 718 & 87,81 & 209,59 & 87,85 & 201,03 & 181,72 & 153,60 \\
PPKS 239 & 83,03 & 128,73 & 121,35 & 226,47 & 342,56 & 180,42 \\
Langkat & 114,62 & 122,07 & 168,04 & 187,21 & 155,94 & 149,57 \\
\hline Rataan & 92,54 & 108,18 & 106,10 & 195,65 & 215,45 & 143,58 \\
\hline Keterangan & $120,17 \mathrm{e}$ & $154,38 \mathrm{c}$ & $124,22 \mathrm{~d}$ & $199,67 \mathrm{~b}$ & $222,81 \mathrm{a}$ & \\
\hline
\end{tabular}

Keterangan: Angka yang diikuti notasi yang sama pada kolom yang sama menunjukkan berbeda tidak nyata pada taraf 5\% menurut Uji Jarak Berganda Duncan. 


\section{Efisiensi Penggunaan Hara}

Efisiensi penyerapan hara $\mathrm{N}$ pada masing-masing varietas diperoleh dengan cara membandingkan selisih serapan $\mathrm{N}$ yang diberi pupuk dengan serapan $\mathrm{N}$ yang tidak diberi pupuk dibagi dengan jumlah hara yang diberikan dalam satuan persen. Kriteria nilai efisiensi serapan hara secara umum adalah untuk $\mathrm{N}=40-60 \%, \mathrm{P}=15-20 \%$ dan $\mathrm{K}=40$ $60 \%$ (Rosmarkam \& Yuwono, 2002). Efisiensi penggunaan $\mathrm{N}$ pada tujuh varietas yang diteliti dengan pemberian $25 \%, 50 \%$, $75 \%$ dan $100 \%$ rekomendasi pemupukan $\mathrm{N}$ tertera pada Tabel 4.

Hasil penelitian menunjukkan nilai efisiensi penggunaan hara pada setiap varietas berbeda - beda pada tingkatan pemberian dosis pupuk yang diuji. Pada varietas Avros pemberian dosis 50 dan $75 \%$ rekomendasi pemupukan $\mathrm{N}$ memiliki nilai efisiensi 42,28 dan $41,31 \%$ (Tabel 4) yang sudah memasuki kriteria nilai efisiensi penyerapan hara yang optimal. Rosmarkam \& Yuwono (2002) menyatakan Nilai efisiensi serapan hara secara umum untuk $\mathrm{N}=40-60 \%$, Hara yang tidak dapat diserap oleh tanaman dapat disebabkan hilang karena terlindi, menguap, terbawa air limpasan dan erosi, tersemat, diambil oleh mikrobia, atau mengendap di dalam tanah.

Varietas Yangambi memiliki kriteria nilai efisiensi penggunaan hara optimal pada pemberian $25 \%$ pupuk $\mathrm{N}$ yaitu sebesar 43,88\%. Pada varietas PPKS 718 nilai efisien penggunaan hara tertinggi diperoleh pada perlakuan dosis 75 dan $100 \%$ rekomendasi pemupukan N (42,52 dan 42,29\%), sedangkan varietas PPKS 239 pada 50\% rekomendasi pemupukan $\mathrm{N}(41,7 \%)$ yang sudah memasuki nilai efisiensi penggunaan hara yang optimal.

Hal ini menunjukkan bahwa setiap varietas bibit kelapa sawit memiliki kemampuan metabolisme dan penyerapan hara dalam jumlah yang berbeda - beda. Dimana penyerapan unsur hara erat kaitannya dengan proses fotosintesis, proses tersebut akan menghasilkan fotosintat yang akan disalurkan dari daun keseluruh bagian tanaman. Semakin tersedia unsur hara dan semakin bagus penyerapan hara maka proses metabolisme akan semakin baik.

Perlakuan yang tidak berbeda nyata pada varietas tersebut diduga perbedaan pertumbuhan akan lebih kelihatan pada saat tanaman mulai dipindah tanam ke lapangan. Pada umur ini varietas bibit kelapa sawit baru menunjukkan responsnya terhadap perubahan perlakuan. Perbedaan akan lebih jelas kelihatan pada rataan tinggi per tahun, potensi produksi, rendemen minyak, produksi CPO, rataan berat tandan dan juga panjang pelepah. Setiap varietas menunjukkan bahwa faktor variasi genetik dari masing - masing varietas yang mempunyai susunan genetik berbeda mengikuti sifat induknya, sehingga akan memiliki respon pertumbuhan dan produksi yang berbeda - beda. Welsh (1981) menyatakan bahwa variasi genetik disebabkan oleh adanya pewarisan sifat genetik dan faktor - faktor lingkungan.

Tabel 4. Efisiensi penggunaan hara pada perlakuan varietas dan tingkat pemberian pupuk $\mathrm{N}$

\begin{tabular}{lllll}
\hline \multirow{2}{*}{ Varietas } & \multicolumn{4}{c}{ Dosis pemupukan N } \\
\cline { 2 - 5 } & $25 \%$ & $50 \%$ & $75 \%$ & $100 \%$ \\
\hline Avros & $6,33 \%$ & $42,28 \%$ & $41,31 \%$ & $37,63 \%$ \\
Simalungun & $12,22 \%$ & $24,90 \%$ & $39,13 \%$ & $25,23 \%$ \\
PPKS 540 & $7,63 \%$ & $26,28 \%$ & $27,82 \%$ & $33,24 \%$ \\
Yangambi & $43,88 \%$ & $29,33 \%$ & $39,68 \%$ & $30,65 \%$ \\
PPKS 718 & $18,30 \%$ & $36,57 \%$ & $42,52 \%$ & $42,29 \%$ \\
PPKS 239 & $3,08 \%$ & $41,70 \%$ & $37,02 \%$ & $27,80 \%$ \\
Langkat & $6,52 \%$ & $32,52 \%$ & $38,88 \%$ & $33,23 \%$ \\
\hline
\end{tabular}




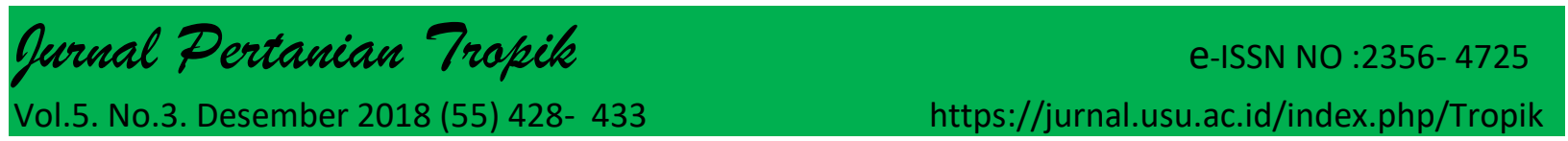

\section{SIMPULAN}

Varietas Avros, Simalungun, PPK 540, Yangambi, PPKS 718, PPKS 239, dan Langkat belum memperlihatkan respons pertumbuhan yang berbeda nyata pada tingkatan pemberian dosis rekomendasi pemupukan N. Perlakuan dosis 100\% rekomendasi pemupukan $\mathrm{N}$ memiliki hasil tertinggi pada parameter bobot kering tajuk, dan serapan hara $\mathrm{N}$ tanaman. Varietas Yangambi dengan pemupukan 25\% rekomendasi memiliki nilai efisiensi penggunaan hara tertinggi yang optimal, Avros, dan PPKS 239 pada taraf 50\%, sedangkan Simalungun, PPKS 718 dan Langkat pada taraf 75\% dan PPKS 540 pada tingkat pemberian $100 \%$ rekomendasi pemupukan $\mathrm{N}$.

\section{DAFTAR PUSTAKA}

Anbessa, Y.and Juskiw, P. 2012. Review: Strategies to Increase Nitrogen Use Efficiency of Spring Barley. Canadian Journal of Plant Science. 92: $617-625$.

Bingham, I. J., Karley A. J., White P. J., Thomas W. T. B., and Russell J. R. 2012. Analysis of Improvements in Nitrogen Use Efficiency Associated with 75 Years of Spring Barley Breeding. European Journal of Agronomy. $42: 49-58$.

Direktorat Jenderal Perkebunan. 2015. Rencana Strategis Direktorat Jenderal Perkebunan Tahun 20152019. Jakarta.
Djajakirana, G. 2001. Kerusakan Tanah sebagai Dampak Pembagunan Pertanian. Makalah disampaikan pada seminar petani "Tanah sehat titik tumbuh pertanian ekologis"di Sleman. 30 Oktober 2001

Fried, George H. \& George J. Hademenos. 2000. Scahum's Outlines BIOLOGI Edisi Kedua. Erlangga. Jakarta.

Hirel, B., Le Gouis, J., Ney, B., and Gallais, A. The Challenge of Improving Nitrogen Use Efficiency in Crop Plants: Towards a More Central Role for Genetic Variability and Quantitative Genetics within Integrated. J. Exp. Bot. 2007. 58. 2369 $-2387$.

Nyakpa, M. Y., N. Hakim, M.R. Saul, M.A. Diha, G.B. Hong, H.H. Bailey. 1988. Kesuburan Tanah. Penerbit Universitas Lampung. Bandar Lampung.

Ramadhaini RF, Sudradjat, Wachjar A. 2014. Optimasi Dosis Pupuk Majemuk NPK dan Kalsium pada Bibit Kelapa Sawit (Elaeisguineensis Jacq.) di Pembibitan Utama. J. Agron. Indonesia Vol. 42 (1) : $52-58$.

Rosmarkam, A., N. W. Yuwono. 2002. Ilmu Kesuburan Tanah. Kanisius. Yogyakarta

Welsh, J.R. 1981. Dasar-Dasar Genetika dan Pemuliaan Tanaman. Diterjemahkan oleh Johanis P. Mogea dari Fundamental of Plant Genetic and B reeding. Erlangga. Jakarta. $224 \mathrm{hlm}$. 
